Review

\title{
DNA Hybridization Sensors Based on Electrochemical Impedance Spectroscopy as a Detection Tool
}

\author{
Jin-Young Park ${ }^{1}$ and Su-Moon Park ${ }^{2, *}$ \\ 1 Department of Chemistry, Pohang University of Science \& Technology, Pohang 790-784, Korea; \\ E-Mail: parkjin@postech.edu \\ 2 Interdisciplinary School of Green Energy Engineering, Ulsan National Institute of Science \& \\ Technology, Ulsan 689-805, Korea \\ * Author to whom correspondence should be addressed; E-Mail: smpark@unist.ac.kr; \\ Tel.: +82-52-217-2916; Fax: +82-52-217-2909.
}

Received: 30 September 2009; in revised form: 28 October 2009 / Accepted: 11 November 2009 / Published: 26 November 2009

\begin{abstract}
Recent advances in label free DNA hybridization sensors employing electrochemical impedance spectroscopy (EIS) as a detection tool are reviewed. These sensors are based on the modulation of the blocking ability of an electrode modified with a probe DNA by an analyte, i.e., target DNA. The probe DNA is immobilized on a self-assembled monolayer, a conducting polymer film, or a layer of nanostructures on the electrode such that desired probe DNA would selectively hybridize with target DNA. The rate of charge transfer from the electrode thus modified to a redox indicator, e.g., $\left[\mathrm{Fe}(\mathrm{CN})_{6}\right]^{3-/ 4}$, which is measured by EIS in the form of charge transfer resistance $\left(R_{\mathrm{ct}}\right)$, is modulated by whether or not, as well as how much, the intended target DNA is selectively hybridized. Efforts made to enhance the selectivity as well as the sensitivity of DNA sensors and to reduce the EIS measurement time are briefly described along with brief future perspectives in developing DNA sensors.
\end{abstract}

Keywords: DNA; self-assembled monolayers; conducting polymers; nanostructures; EIS

\section{Introduction}

A DNA sensor based on electrochemical impedance spectroscopy (EIS) detection is a device that transduces changes in interfacial properties between the electrode and the electrolyte induced by DNA 
hybridization, conformational changes, or DNA damages to an electrical signal. In most DNA sensors, the target DNA must be labeled with a fluorophore [1-3], magnetic beads [4], or an enzyme [5] for its detection. On the contrary, DNA sensors based on EIS detection are label-free and, thus, possess advantages of low cost, simplicity, and ease of miniaturization. As a result, the interfacial impedance, which is obtained upon application of a small AC voltage overlaid on a DC bias potential to the sensing electrode and the AC current obtained thereof in the steady state, has been frequently employed for sensing various analytes by biosensors. Biosensors of these types have been constructed for the immunoassay and enzyme-based biosensing, as well as DNA and microorganism analyses; the subject has recently been reviewed by Guan et al. [6]. Other electrochemical techniques used for detection include cyclic voltammetry [7,8], differential pulse voltammetry [9-13], and amperometry [14], which have also been investigated for improvement of their sensitivity. However, when the differences in current are not significant in a low target concentration range, the EIS technique is more favorable than other electrochemical detection techniques in that significantly large differences are usually obtained due to the inverse relation of the impedance with the current, i.e., $\Delta R(Z)=\Delta V / \Delta I$.

Figure 1. Schematic diagram for an electrode/electrolyte interface in a faradaic sensor and its exemplary model circuit [15].

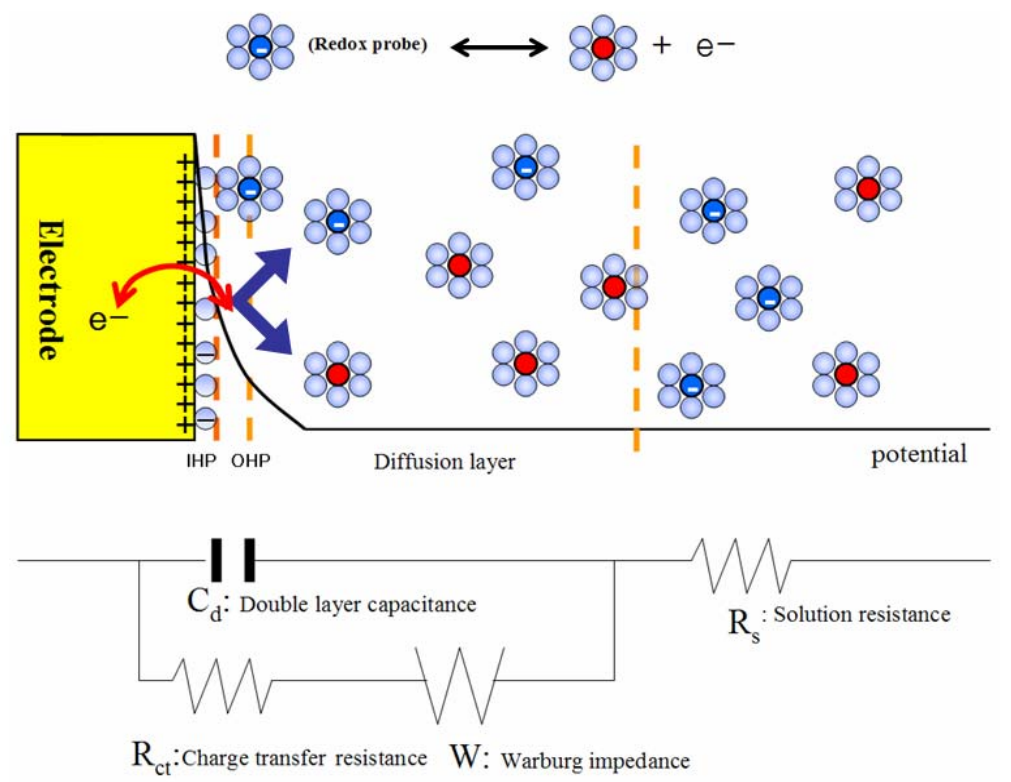

An electrode/electrolyte interface may be simplified as shown by the schematic diagram in Figure 1. When an electrode is electrified by an applied DC potential, solvated counter ions form an electrical double layer by aligning along the electrode surface, which is represented by the so-called double layer capacitor with a capacitance of $C_{\mathrm{d}}$. The electron transfer to/from the electroactive species, which may approach the electrode as close as two solvent molecules away in the outer Helmholtz plane (OHP), takes place across the inner Helmholtz plane (IHP) by overcoming the activation barrier, $R_{\mathrm{p}}$, which is termed a polarization resistance, and the solution resistance, $R_{\mathrm{s}}$. Once the electron transfer gets started, the Warburg impedance $(W)$ due to the mass transport begins to play a role in determining the electrode kinetics. In the non-faradaic EIS detection with no redox indicator added, the capacitance or the dielectric constant of the probe layer can be utilized as a main sensing signal. The charge-transfer 
resistance $\left(R_{\mathrm{ct}}\right)$, which is the polarization resistance at an equilibrium potential, is utilized as a main indicator in the faradaic EIS detection. A redox pair such as $\left[\mathrm{Fe}(\mathrm{CN})_{6}\right]^{3-/ 4-}$ or $\left[\mathrm{Ru}\left(\mathrm{NH}_{3}\right)_{6}\right]^{2+/ 3+}$ is frequently used as a redox indicator for the electrode kinetics at the interface, which is modified by a substrate layer as well as probe and target DNAs on the electrode surface. Thus, the $R_{\mathrm{ct}}$ values indicate how crowded the electrode surface is when it is modified by a functional molecule, which is capable of selectively capturing a given analyte. The $R_{\mathrm{ct}}$ values are determined by how selective binding has taken place with the analyte and how much analyte is in the test solution.

The changes in resistances or capacitances of the interface are induced by the DNA hybridization events with a single-stranded target DNA on a suitably designed probe platform. To improve the performance of the DNA sensor, the probe layer should be constructed using a well-defined surface chemistry preventing the non-specific binding as well as other side reactions so that it would exhibit high selectivity for a specific target DNA. As a result, various DNA sensors have been embodied on the electrodes modified with the various platforms such as self-assembled monolayers (SAMs), mixed SAMs, conducting polymer films, various nanomaterials such as gold nanoparticles, and peptide nucleic acids. The design of the probe layer depends on whether the sensor is of faradaic or non-faradaic nature. For example, a compact SAM or an insulating layer without a leakage current is needed for non-faradaic signal processing while a less-packed SAM or a conductive layer accessible to the redox species are more desirable for a faradaic sensor. Changes in electrical properties occurring at the DNA probe layer are usually extracted using a best fitting model. Each circuit element obtained by fitting impedance responses to an electrical circuit can be utilized for analyzing the type and the amount of target DNA as well as its conformational changes [16,17]. In general, the changes in impedances are linearly related to the surface coverage by a target analyte in a low concentration region, but sometimes it is logarithmically related to the amount for the target analyte in the case of high concentration ranges or the heterogeneous binding between the probe and the target molecules. In a faradaic sensor, the charge-transfer resistance, $R_{\mathrm{ct}}$, is associated with the energy barrier for electron transfer to/from the redox indicator approaching to the electrode surface, which is determined by the change in the crowdedness of the probe layer caused by its binding with target DNA. In a non-faradaic sensor, the capacitance of the probe layer is a main indicator exhibiting the conformational changes of double-stranded DNA due to its hybridization. Katz and Willner have published an excellent review on various biosensors including immunosensors, enzyme based sensors, and DNA sensors employing faradaic and non-faradaic impedance spectroscopy as a detection tool [18]. Berggren et al. also introduced the non-faradaic capacitive biosensors [19].

In the present review, we focus on recently developed DNA sensors constructed on various classes of materials used for modifying electrode surfaces such as self-assembled monolayers, conducting polymers, and nanomaterials, which show high sensitivity and selectivity for various target DNAs using faradaic and non-faradaic impedance spectroscopy as a detection tool. We limit our discussions to DNA as a target analyte and EIS as a detection tool. 


\section{DNA Sensors Based on Self-Assembled Monolayers}

Monitoring $R_{\mathrm{ct}}$ values on SAM modified gold electrode surfaces supporting thiolated probe DNAs is perhaps the most convenient and important method for investigating the DNA hybridization and conformational changes. Thiolated probe DNAs form a self-assembled monolayer on the gold surface due to the high affinity of the thiol group towards gold. Ito et al. detected changes in $R_{\mathrm{ct}}$ values according to the location of the mismatched pair in the DNA duplex on the thiolated probe DNA SAM [20]. To analyze the DNA hybridization kinetics, Li et al. attempted to make real-time measurements of $R_{\mathrm{ct}}$ values and reported an affinity constant of $10^{8} \mathrm{M}^{-1}$ for a perfect match [21]. On the immobilization of a probe DNA molecule with a disulfide, the Li and Kraatz group characterized the B-DNA (native DNA) and M-DNA formed by adding $\mathrm{Zn}^{2+}$ to B-DNA [22-26]. The different charge and conformational characteristics of B-DNA and M-DNA on the surface led to different charge-transfer resistances for the redox indicator ions. Thus, they discriminated target DNA with one mismatch against a complementary DNA based on the difference in the $R_{\mathrm{ct}}$ values between M-DNA and B-DNA in presence of the $\left[\mathrm{Fe}(\mathrm{CN})_{6}\right]^{3-/ 4-}$ redox indicator. Later, they examined eight metal ions including alkaline earth metal ions $\left(\mathrm{Mg}^{2+}\right.$ and $\left.\mathrm{Ca}^{2+}\right)$, trivalent ions $\left(\mathrm{Al}^{3+}\right.$ and $\left.\mathrm{La}^{3+}\right)$, and divalent transition metal ions $\left(\mathrm{Ni}^{2+}, \mathrm{Cu}^{2+}, \mathrm{Cd}^{2+}\right.$, and $\left.\mathrm{Hg}^{2+}\right)$ and reported that these metal ions cause decreases in $R_{\mathrm{ct}}$ values. The difference of the charge transfer resistance $\left(\Delta R_{\mathrm{ct}}\right)$ of ds-DNA films in the presence and absence of these metal ions was different and particular to a given metal ion [27]. Further, the $\Delta R_{\mathrm{ct}}$ values for ds-DNA films with a single A-C mismatch are smaller than those of fully matched ds-DNA films for $\mathrm{Ca}^{2+}$.

The charge-transfer resistance to the redox indicator is governed by surface blocking effects exerted by the hybridization of target DNA with the probe and the charged state of the probe layer on the electrode. In efforts to amplify the sensing signal, i.e., the $R_{\mathrm{ct}}$ value, target DNA tagged with negatively charged liposome was utilized to enhance the repulsion between the target DNA and the negative charged redox indicator ions, i.e., $\left[\mathrm{Fe}(\mathrm{CN})_{6}\right]^{3-/ 4-}$, leading to detection limits of $1 \times 10^{-12} \sim 1 \times 10^{-13} \mathrm{M}[28,29]$. To enhance the blocking ability of the sensing electrode for more sensitive detection of hybridization, an insulating layer formed by precipitation of an enzyme-catalyzed insoluble product was taken advantage of [28,29]. In this case, the pathway of electron transfer to/from the electrode was very effectively blocked and changes in $R_{\mathrm{ct}}$ values were remarkably enhanced upon hybridization leading to a low detection limit of $1.2 \mathrm{pM}$.

Immobilization of thiolated probe DNA on the gold surface with an optimum density is a key technique for improving DNA sensing efficiencies. To control the radii around the probe DNAs to secure appropriate space for hybridization, mixed SAMs obtained from an appropriate ratio of thiolated probe DNA molecules and other blocking thiols have been frequently utilized. Since Herne and Tarlov attempted to prepare a mixed SAM of thiolated ss-DNA and mercaptohexanol (MCH) for more effective hybridization in their early study [30], two-step methods, in which probe DNA is first immobilized on the surface followed by the formation of the MCH SAM, have been widely employed for DNA sensors [16,21,31]. Keighley et al. [32] studied the possibility of obtaining an optimum density of immobilized probe DNAs on the gold surface by simultaneously immobilizing both thiolated probe DNA and MCH instead of using the two-step method introduced by Herne and Tarlov. Based on EIS measurements, they found that the degree of increase in the charge-transfer resistance 
for the $\left[\mathrm{Fe}(\mathrm{CN})_{6}\right]^{3-/ 4}$ redox indicator during the hybridization is related to the probe density obtained by controlling the fraction of thiolated probe DNA in the mixed solution. As a result, the increase in charge-transfer resistance was observed only above a threshold probe surface density of $2.5 \times 10^{12} \mathrm{~cm}^{-2}$ due to the repulsion between negatively charged DNA and the negative redox indicator ions, i.e., the $\left[\mathrm{Fe}(\mathrm{CN})_{6}\right]^{3-/ 4-}$ pair. The optimum probe density was found to be $5.4 \times 10^{12} \mathrm{~cm}^{-2}$, which was obtained from a solution containing both thoiolated DNA and $\mathrm{MCH}$ with a DNA mole fraction of $20 \%$. Kjällman et al. employed thiolated polyethylene glycol [PEG: $\mathrm{CH}_{3}-\left(\mathrm{CH}_{2} \mathrm{CH}_{2} \mathrm{O}\right)_{6}-\mathrm{CH}_{2} \mathrm{CH}_{2} \mathrm{SH}$ ] as an alternative for $\mathrm{MCH}$ for controlling the probe density and blocking the non-specific binding [33]. On the mixed SAM consisting of PEG and the hairpin DNA probe as displayed in Figure 2, the conformational change of the hairpin probe caused by hybridization induced an increase or decrease in the $R_{\mathrm{ct}}$ value for electron transfer to/from $\mathrm{Fe}\left(\mathrm{CN}_{6}\right)^{3-/ 4}$. This strategy lowered the detection limit down to $4.7 \mathrm{fM}$, while enhancing the high selectivity, for complementary target DNA with respect to a one-mismatched target. Kafka et al. also reported a label-free DNA sensor on a mixed SAM prepared from thiolated probe DNA and 4-mercapto-1-butanol (MCB), which led to the increase in the $R_{\mathrm{ct}}$ value as well [34]. The mixed system obtained from the solution containing thiolated probe DNA and MCB exhibited the high specificity to the complementary target by showing a large increase in the $R_{\mathrm{ct}}$ value while a negligible change, or even a decrease, was observed for a single mismatched target.

Figure 2. (1) The immobilization of a hairpin structured probe and PEG onto the gold surface and (2) hybridization with a complementary target [31].

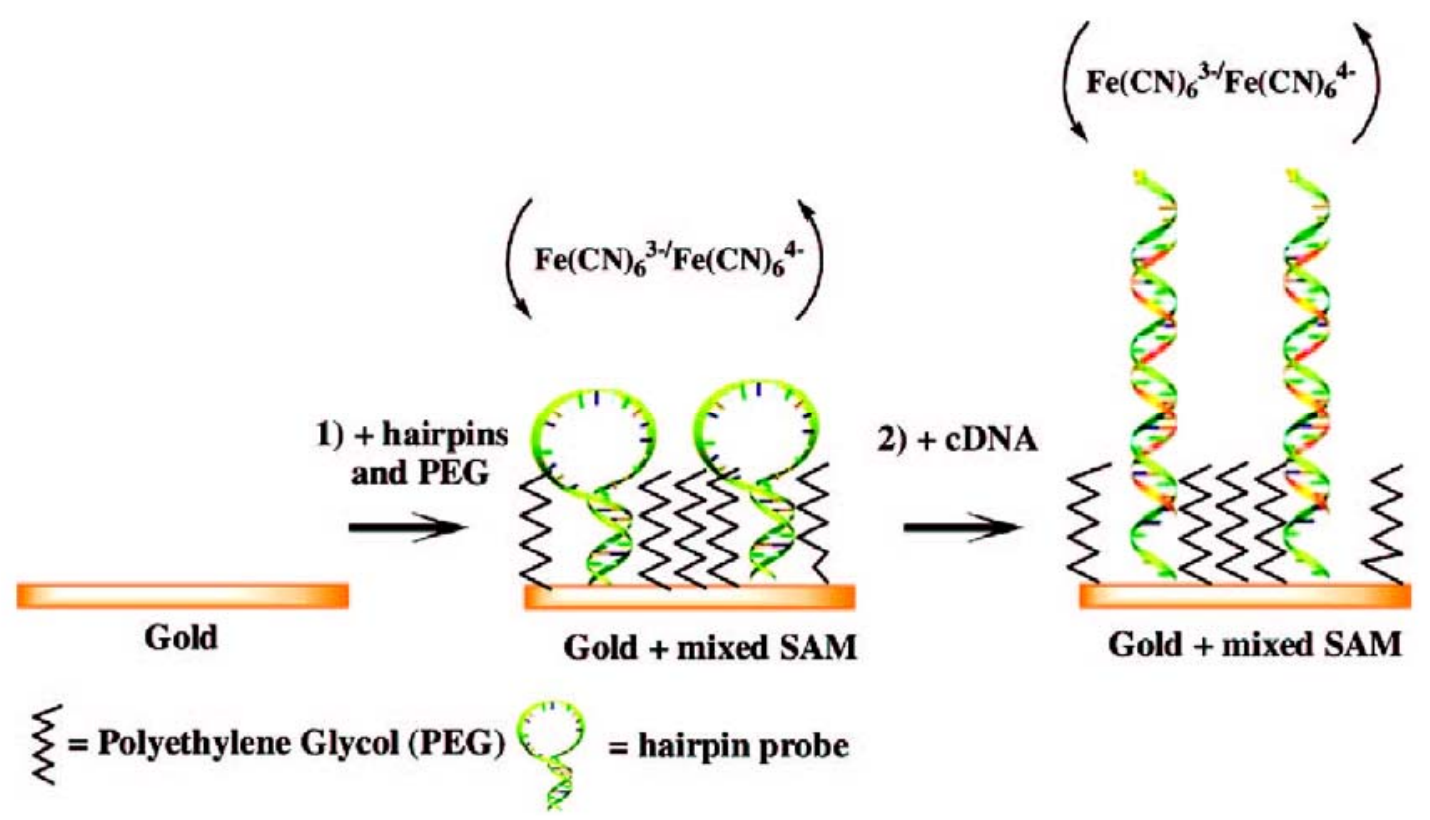

The SAM prepared using dendrimer molecules is also a useful system for DNA sensing due to their biocompatibility and a sufficient number of functional groups needed for chemical immobilization at the surface. SAMs obtained from the poly(amidoamine) (PAMAM) dendrimer of a spherical shape containing a large number of amine groups at its surface have been characterized and frequently employed for constructing various biosensors by a few groups [35-37]. The Zhu and Fang group immobilized probe DNA using phosphoramidate bonds formed between amine groups of PAMAM and phosphate groups of DNA on the forth-generation PAMAM dendrimer/mercaptoacetic layer on 
the gold surface [38]. They reported that the target DNA conjugated with the carboxyl-terminated PAMAM dendrimer was hybridized with the probe DNA covalently bound to the mercaptoacetic acid SAM layer on gold [39]. A large increase in $R_{\mathrm{ct}}$ was detected for complementary hybridization while the change in the charge transfer resistance was so small for hybridization with DNAs containing mismatches. The negatively charged PAMAM dendrimer is helpful for the $R_{\mathrm{ct}}$ signal amplification due to the enhanced repulsion between the target DNA conjugated with negatively charged PAMAM and the $\left[\mathrm{Fe}(\mathrm{CN})_{6}\right]^{3-/ 4}$ redox indicator. As described above, the PAMAM dendrimer can be utilized for the immobilization of probe DNA or the signal enhancement via target-labeling. Probe DNA of an appropriate density obtained by a cone-shaped dendrimer showed very high specificity to the complementary target, leading to different responses of $R_{\mathrm{ct}}$ values in the presence of $\left[\mathrm{Fe}(\mathrm{CN})_{6}\right]^{3-/ 4-}$ depending on the location of the mismatched pair in the duplex [40]. Thus, various kinds of dendrimers can be diversely utilized for DNA sensors by virtue of their controlled sizes, sufficient functional groups, and unique shapes.

Recently, the Li and Kraatz group took advantage of small molecule [41] and protein [42] binding to ds-DNA to exploit more sensitive detection of single nucleotide mismatches. A small molecule called naphthyridine-azquinolone (Npt-Azq) was found to bind the G-A region of the mismatch, causing a significant change in the $R_{\mathrm{ct}}$ values for DNA/Npt-Azq films, in which the DNA was a 20-mer containing an A-A mismatch, which allowed the unequivocal detection of the A-A mismatch [41]. The advantage of this approach is that it is specific to the A-A mismatch. Another approach was the use of MutS protein for the detection of mismatches [42]. MutS was found to bind ds-DNA with a single nucleotide mismatch at its top, resulting in a significant increase in $\Delta R_{\mathrm{ct}}$ value. Eight different single-nucleotide mismatches were detected by this method and a C-A mismatch was detectable down to a concentration of as low as $100 \mathrm{pM}$ of the target strand.

\section{DNA Sensors Based on Conducting Polymers}

A conducting polymer containing an extended $\pi$-conjugated structure can be very sensitive even to small perturbations at the interface thanks to its high electrical conductivity and electron transfer capabilities when the interface is covered by its film. Biocompatible conducting polymers can be variably modified for immobilization of probe DNA via covalent linking or electrostatic interactions. The conductivity of the conducting polymer electrochemically deposited on the electrode surface can be modulated by changing the $\mathrm{pH}$ of the medium, the electrochemical potential, and/or the electrolyte. Because of these characteristics and other advantages, a number of conducting polymers such as polyaniline, polythiophene, polypyrrole, and their derivatives have been utilized extensively for the construction of biosensors including DNA sensors. Rahman et al. have recently reviewed biosensors based on conducting polymers [43].

As a simple approach, polypyrrole (PPy) was used directly for the immobilization of a DNA probe based on the electrostatic attraction between electrochemically oxidized-PPy and negatively charged oligonucleotides $[44,45]$. The enhancement in the $R_{\mathrm{ct}}$ value was achieved by using CdS nanoparticle tagged-probe DNA for the hybridization of target DNA physically entrapped in the PPy film $[46,47]$. In these cases, however, the oligonucleotides were randomly attached to the polymer surface showing low hybridization efficiencies. Thus, PPy films derivatized at either the N- or 3-positions were utilized 
for the construction of DNA sensors [48,49]. Peng et al. reported DNA sensors, in which a poly[pyrrole-co-4-(3-pyrrolyl) butanoic acid] film, which was electrochemically synthesized from the pyrrole monomer and 4-(3-pyrrolyl) butanoic acid, was used as a DNA immobilization platform [50,51]. On a DNA sensor based on a copolymer film, the $R_{\mathrm{ct}}$ value was increased with an increase in the target DNA concentration. In agreement with this result, the charge-transfer rate constant to/from the redox couple, $\left[\mathrm{Fe}(\mathrm{CN})_{6}\right]^{3-/ 4}$, obtained from Equation 1 using the $R_{\mathrm{ct}}$ value:

$$
k_{a}^{0}=\frac{R T}{n^{2} F^{2} A R_{\mathrm{ct}}} \times \frac{1}{C_{0}^{*(1-\alpha)} C_{\mathrm{R}}^{* \alpha}}
$$

also decreased with an increase in the target DNA concentration. Later, they also reported preparation of variously functionalized PPy copolymers using pyrrole, 3-pyrrolylacrylic acid (PAA), 5-(3-pyrrolyl)-2,4-pentadienoic acid (PPDA), and 3-pyrrolylpentanoic acid (PPA) [52,53]. After the copolymer was electrochemically synthesized at $1.0 \mathrm{~V}(v s . \mathrm{Ag} / \mathrm{AgCl})$, amine-modified probe DNA was covalently attached to the carboxyl group of the side chain of the copolymer through the (1-ethyl-3-(3-dimethylaminopropyl) (EDC) carbodiimide coupling. When the hybridization efficiency was compared with the results obtained by faradaic impedance measurements, the poly(Py-co-PDDA) film containing more conjugated side chains showed the largest increase in $R_{\mathrm{ct}}$ upon complementary hybridization as shown in Figure 3 . This indicates that the polymer backbone conjugated with more probe DNA molecules can be much more susceptible to the change in the DNA probe layer due to the hybridization.

Figure 3. Nyquist plots for electrochemical impedance measurements on electrodes modified with poly(Py-co-PPDA) (A) and poly(Py-co-PPA) (B) in the presence of $5.0 \mathrm{mM}$ $\left[\mathrm{Fe}(\mathrm{CN})_{6}\right]^{3-} /\left[\mathrm{Fe}(\mathrm{CN})_{6}\right]^{4-}$ : before (a) and after (b) immobilization of probe DNA, then after incubation (c) with a 20.2 nM DNA target solution [52].
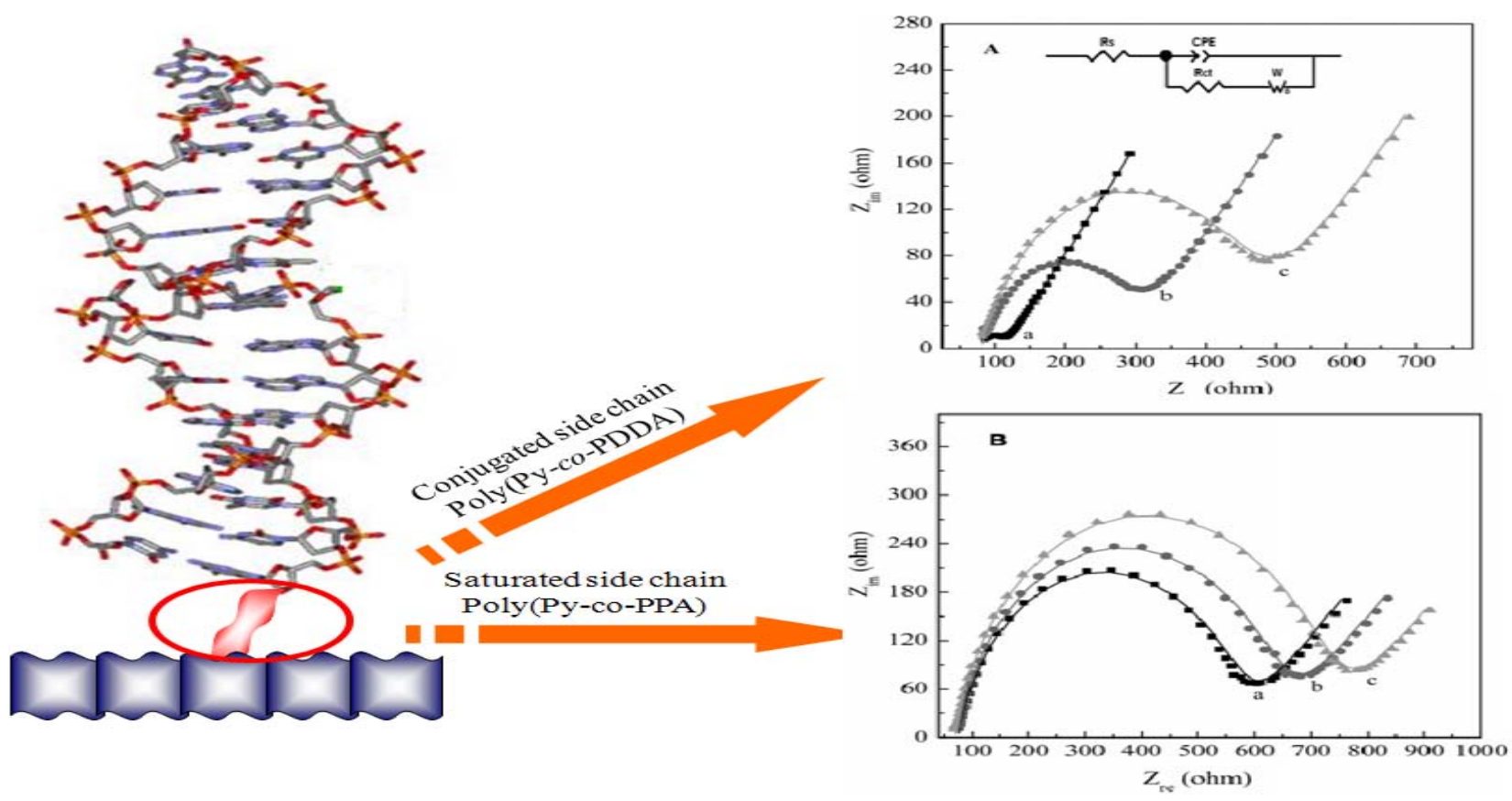
The detection of the DNA hybridization reaction was also accomplished on the carboxylated polyterthiophene film prepared on the glassy carbon electrode employing non-faradaic impedance spectroscopy without any indicators or labeling molecules present [54]. An amine-modified DNA probe was covalently bound to carboxyl groups on the surface of the functionalized polyterthiophene film. When compared by differences in logarithmic impedances at a fixed frequency of $1.0 \mathrm{kHz}$, a significant decrease in impedance was observed only for the complementary target, not in the mismatched targets, suggesting that the complementary double-stranded DNA shows an enhanced conductivity in comparison with its single-stranded DNA counterpart. The acrylated polyterthiophene was also used for the DNA sensor through EDC coupling with amine-terminated probe DNA [55,56]. The hybridization efficiency was compared in the reduced and oxidized states of the acrylated polyterthiophene film employing both faradaic and non-faradaic EIS. The result showed that the hybridization was detected more efficiently in the oxidized state of the film displaying a large difference in the phase angle at a fixed frequency. According to Scheme 1, Gautier et al. utilized the thiophene matrix covalently coupled with amine modified-probe DNA as a platform for the DNA sensor [57-59]. They reported different responses upon hybridization in terms of the phase angle in Bode plots and the impedance modulus when examined in faradaic and non-faradaic modes. After the hybridization with a complementary target, the impedance modulus was decreased in the non-faradaic mode on the contrary to the increase in the faradaic mode. When the relaxation processes were monitored at $50 \mathrm{~Hz}$ and $5 \mathrm{kHz}$ by non-faradaic impedance spectroscopy, the first relaxation process at $50 \mathrm{~Hz}$ revealed the hybridization with a decreased phase angle and the second relaxation process at the $5 \mathrm{kHz}$ [57] was related to the length of the target sequence.

Scheme1. Immobilization of ODN

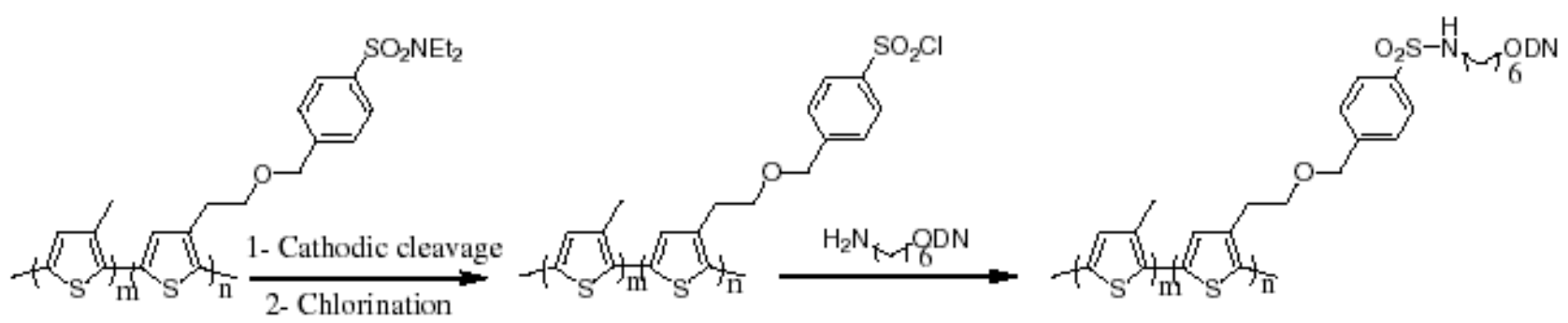

Davis et al. reported that a highly sensitive $1 \mathrm{fg} / \mathrm{mL}$ detection limit was achieved by fabricating the screen-printed electrode modified with electrostatic adsorption of the DNA probes onto the polyethyleneimine film or by incorporating DNA probes into the electrodeposited polyaniline or polydiaminobenzene film [60,61]. They detected the hybridization and discriminated the mismatched DNA against the complementary target on the screen printed electrode modified with various conducting polymers based on the measurement of the mean relative impedance over all frequencies in a non-faradaic mode. To obtain the relative impedance at each frequency, they divided the impedance obtained at a given time interval during the hybridization reaction by the initial impedance value at a selected single frequency. The drop in the impedance observed during the complementary hybridi-zation was caused by the enhanced conductivity of double stranded DNA with respect to that of single strands. Weng et al. fabricated the electrochemical DNA sensor on the boron doped diamond 
(BDD) electrode modified by polyethylimine. The relative impedance at a fixed frequency of $10 \mathrm{~Hz}$ without any redox indicator present was decreased with an increase in the target DNA concentration with a good sensitivity with a detection limit of $10^{-19} \mathrm{gm} \mathrm{L}^{-1}$ [62]. Gu et al. attempted to develop DNA sensors on polyaniline and polyacrylate copolymer modified boron-doped diamond electrodes [63]. On the modified BDD, the detection limit was $2.0 \times 10^{-8} \mathrm{M}$ based on the measurement of the decrease in impedances. When the flat-band potential of the BDD was obtained from the Mott-Schottky plot, in which $1 / C^{2}$ was plotted against the potential, they observed negative shifts in flat-band potentials upon hybridization with a complementary target, suggesting that the hybridization induce the decreased band bending of the p-type semiconductor. They further reported conducting polymer nanocomposites mixed with nanomaterials such as the carbon-nanotubes and $\mathrm{TiO}_{2}$ nanoparticles or nanotubes as a platform for DNA sensors for immobilizing the probe DNA [64-66].

\section{DNA Sensors Based on Nanomaterials}

A variety of nanomaterials such as nanoparticles, nanowires, and nanotubes have been used for constructing DNA sensors. In this section, we briefly review EIS-based DNA sensors constructed using the nanomaterials.

Metal nanoparticles have been utilized for enhancing impedance signals by increasing the number of immobilized probe DNA molecules [67]. The Xu and Fang group showed that CdS nanoparticles can be utilized for signal amplification in faradaic-impedance based DNA sensors [68]. A target DNA labeled with CdS nanoparticles was hybridized with amine-modified probe DNA covalently bound to the mercaptoacetic acid monolayer on the gold surface. The $R_{\mathrm{ct}}$ value for the $\left[\mathrm{Fe}(\mathrm{CN})_{6}\right]^{3-/ 4-}$ redox indicator was remarkably increased upon hybridization for the complementary target due to the high density negative charges, space blocking, and semiconducting properties of the CdS nanoparticles, which lowered the detection limit down to $1.43 \times 10^{-10} \mathrm{M}$. Also, gold nanoparticles deposited on the gold electrode were employed as a platform for the immobilization of thiolated probe DNA [69]. The difference in $R_{\mathrm{ct}}$ values before and after hybridization showed a linear relation with the concentration of the target in a range of $2.0 \times 10^{-12} \sim 9.0 \times 10^{-8} \mathrm{M}$. Bonnani et al. utilized a streptavidin-coated gold nanoparticles for improving the $R_{\mathrm{ct}}$ signal [70]. The probe DNA immobilized on the graphite epoxy composite working electrode by simple physical adsorption was hybridized with a biotinylated complementary oligomer, followed by binding to streptavidin-coated gold nanoparticles for an improvement of the $R_{\mathrm{ct}}$ signal. The relative $R_{\mathrm{ct}}$ variance for the $\left[\mathrm{Fe}(\mathrm{CN})_{6}\right]^{3-/ 4-}$ pair was magnified with an increase in the target concentration due to the electrostatic repulsion and steric hindrances. The detection limit was improved from 26.5 pmol to 11.8 pmol in comparison to the non-amplification method. In their more recent report, they described the immobilization of the amine-terminated probe DNA by carbodiimide chemistry on the screen-printed electrode, which was modified by carboxylated multi-walled carbon nanotubes [71]. Based on the same amplification technique of streptavidin-coated gold nanoparticles, they obtained a magnificently enhanced detection limit of 22 fmol on the multi-wall carbon nanotube-modified screen printed electrode. In addition to this, the signal enhancement technique using gold nanoparticles have been frequently applied to aptamer sensors recognizing the specific proteins as well as DNA [72-75]. The Li and Zhang group utilized gold nanoparticles electrodeposited on the glassy carbon electrode for the immobilization of the thiolated 
aptamer and the signal enhancement according to Scheme 2 [75]. Increases in $R_{\mathrm{ct}}$ values were monitored in a concentration range of thrombin from $0.12 \mathrm{nM}$ to $30 \mathrm{nM}$. Using the $\left[\mathrm{Fe}(\mathrm{CN})_{6}\right]^{3-/ 4-}$ redox indicator, Deng et al. detected thrombin through the increase in $R_{\mathrm{ct}}$ on the sandwich system of aptamer/thrombin/ aptamer functionalized Au nanoparticles for a cascaded signal amplification [76]. The three level amplification was accomplished by the attachment of aptamer-functionalized $\mathrm{Au}$ nanoparticles as a first step, the steric hindrance by the enlargement of aptamer Au nanoparticles as a second step, and the increased electrostatic repulsion by the sodium dodecylsulfate (SDS) stabilizer of aptamer-Au nanoparticles as a final step; this series of procedures enabled a detection limit of $100 \mathrm{fM}$ to be obtained. Magnetic nanoparticles were also used as a DNA binding platform as gold nanoparticles.

Scheme 2. Gold nanoparticles-based aptamer sensor: the thiolated aptamer is first immobilized on the gold nanopartices covering a glassy carbon electrode (GCE), which is then followed by the recognition of thrombin proteins. Here TBA is thrombin aptamer and HT is hexane thiol [75].
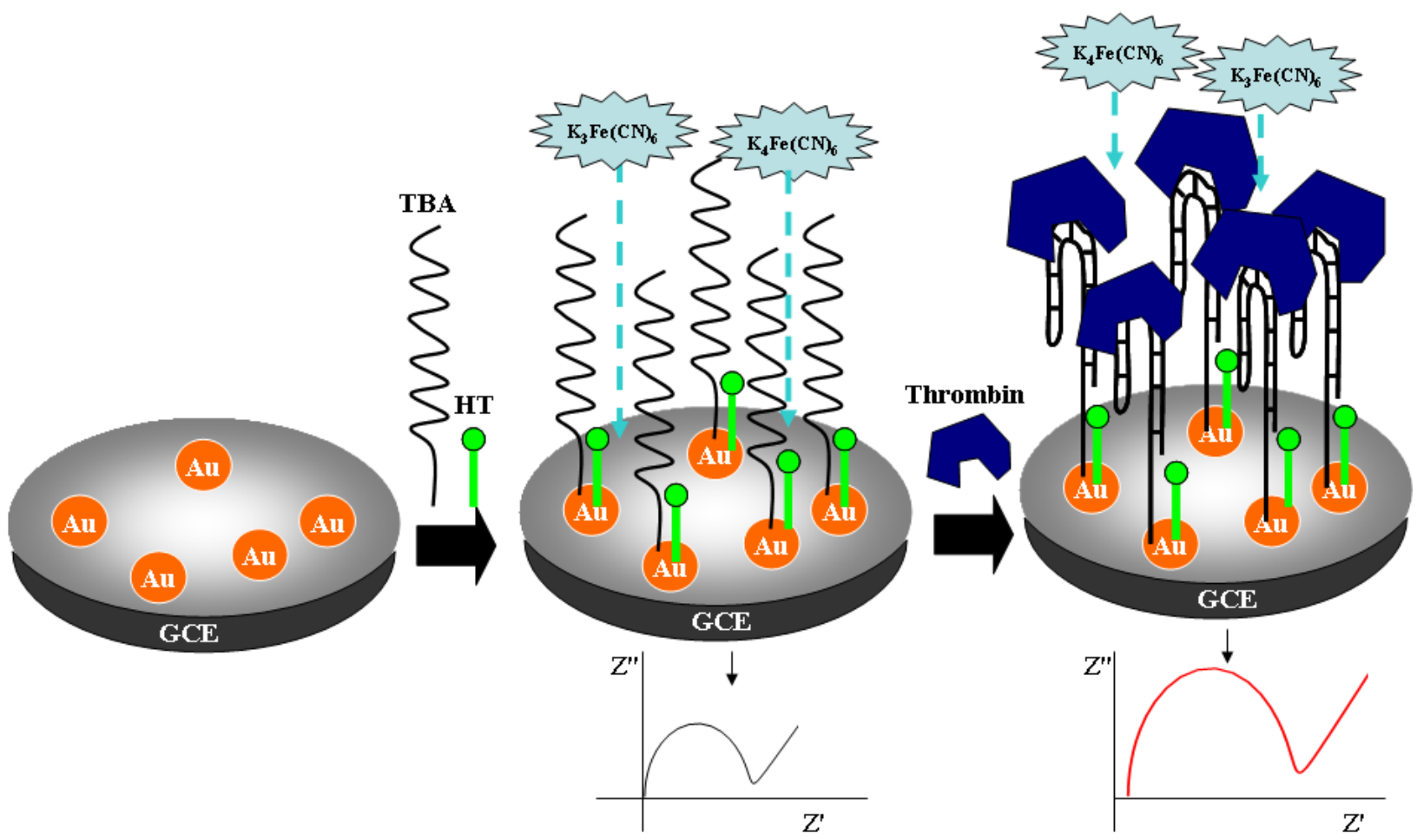

Biotin-modified hepatitis-B virus (HBV) probe DNA was immobilized on the streptavidin coated magnetic nanoparticles by the streptavidin-biotin interaction. The magnetic nanoparticles modified with HBV probe DNA was attached to the gold surface, and the hybridization with the target HBV sequence was detected by an increase in resistance using non-faradaic EIS, which led to the detection limit of $50 \mathrm{pmol}$ for a $20 \mu \mathrm{L}$ sample [77]. Another example of the nanoparticle platform as a sensing material is praseodymium oxide nanoparticles with a high dielectric constant, a large band gap, and a high electron affinity [78]. Thiol modified probe DNA attached to the amine-modified praseodymium oxide nanoparticles was allowed to hybridize with its target DNA, which was detected by the decrease in capacitance without a redox indicator present. 
Chemically stable and biocompatible $\mathrm{GaN}$ nanowires have been widely investigated for various applications to biotechnology [79-81]. GaN nanowires have high conductivity due to the substantial charge separation between the surface and the core; thus, strongly negatively charged DNA can induce large changes in the electrochemical behavior of the nanowires. Chen et al. developed a novel DNA sensor based on GaN nanowires as shown in Scheme 3 [82]. The electrical properties of nanowires thus modified were studied by non-faradaic impedance spectroscopy before and after the DNA hybridization. As shown in Scheme 4, the upward band-bending of the as grown GaN nanowires was flattened by complementary hybridization resulting in a decrease in the resistance or the barrier at the GaN/DNA interface. The resistance was shown to be further decreased with an increase in the target DNA concentration down to pico to micromolar levels.

Scheme 3. Schematic diagram of a DNA sensor based on GaN nanowires: (a) nanowires, (b) hydroxylation of the surfaces, (c) modification by 3-mercaptopropyl trimethoxysilane (MPTS), and (d) immobilization of probe DNA, and e) hybridization [82].

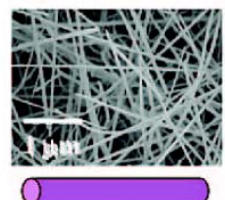

(a)

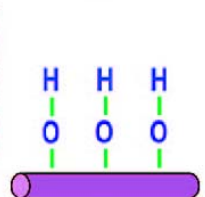

(b)

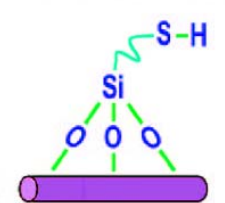

(c)

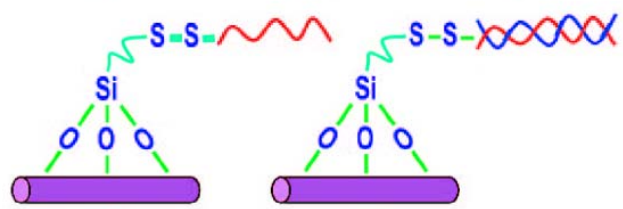

(d)

(e)

Scheme 4. The band-bending of GaN nanowires: (a) bare GaN nanowires in contact with the electrolyte, (b) reduced band-bending due to the immobilization of probe DNA, and (c) further flattening of the band-bending by hybridization. Here GS represents the GaN/solution interface, GD the GaN/DNA interface, and DS the DNA/electrolyte interface [82].

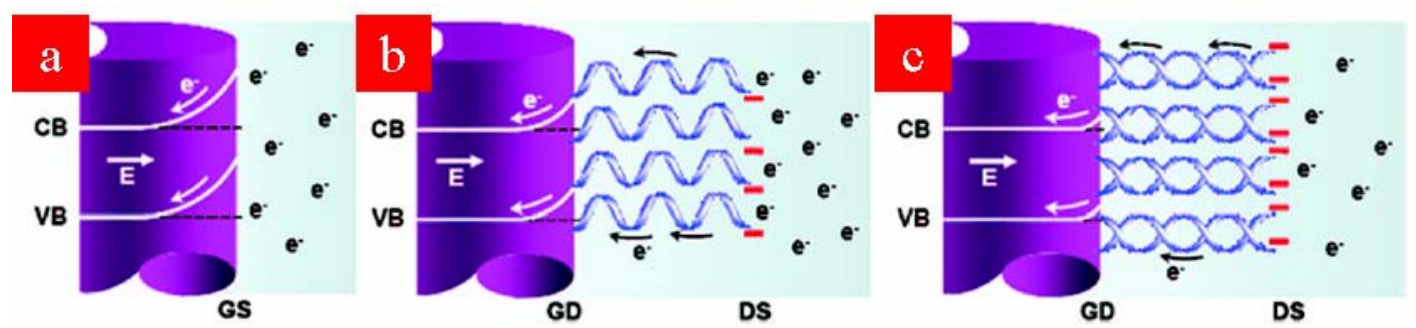

Finally, carbon nanotubes (CNTs) are also one of important candidates for constructing DNA sensors [83-86]. Various applications of CNTs and the related methodologies have been reviewed [86]. Jiang et al. first electropolymerized L-lysine to prepare its polymeric film on carboxylated carbon nanotubes spread on a carbon paste electrode (CPE). The probe DNA was then immobilized on the poly-L-lysine/CNT/CPE by electrostatic attraction. The hybridization of the PAT (phosphinothricin acetyltransferase) gene fragment was monitored by an increase in $R_{\mathrm{ct}}$ values by the faradaic EIS using 
the $\left[\mathrm{Fe}(\mathrm{CN})_{6}\right]^{3-/ 4}$ redox indicator [87] (detection limit to $3.1 \times 10^{-13} \mathrm{~mol} / \mathrm{L}$ ). In addition, a nanocomposite membrane consisting of nanoshuttle-shaped cerium oxide $\left(\mathrm{CeO}_{2}\right)$ particles, single-walled carbon nanotubes and 1-butyl-3-methylimidazolium hexafluorophosphate was also investigated on a glassy carbon electrode for DNA immobilization and its hybridization using the faradaic EIS technique. This nanocomposite system remarkably improved the sensitivity of DNA hybridization detection based on the increase of $R_{\mathrm{ct}}$ for the $\left[\mathrm{Fe}(\mathrm{CN})_{6}\right]^{3-/ 4}$ indicator after hybridization showing a detection limit of $2.3 \times 10^{-13} \mathrm{M}[88]$.

\section{Amperometric and Voltammetric Detection Versus the EIS Detection}

While we have been describing only the EIS method of detection for the DNA sensors thus far, both amperometric and voltammetric detection methods had widely been used in earlier studies [89]. Although no direct comparison of these detection methods with the EIS technique is available for DNA sensors, recent studies on other biosensors demonstrate that the EIS detection is much preferred to other electrochemical methods including amperometric, voltammetric, and/or potentiometric methods. In recent studies, Park et al. demonstrated that EIS measurements can provide significantly more sensitive responses than cyclic voltammograms (CVs) do [90,91]. In one example, they monitored the kinetics for the esterification reaction between boronic acid, which is immobilized on the gold electrode via the formation of a thiophene-3-boronic acid SAM, and glycated hemoglobin $\left(\mathrm{HbA}_{1 \mathrm{c}}\right)$ in solution with the $\left[\mathrm{Fe}(\mathrm{CN})_{6}\right]^{3-/ 4-}$ indicator present to probe how far the reaction proceeded [90]. When the $\mathrm{HbA}_{1 \mathrm{c}}$ molecule reacts with boronic acid on the electrode, its surface would be effectively blocked. In their experiments, both impedance and cyclic voltammetric measurements were made in real time sequentially by applying the waveform shown in Figure $4 \mathrm{a}$, in which a $10 \mathrm{mV}$ step was applied for the first $2.5 \mathrm{~s}$ to record an impedance spectrum in a full frequency region from about $10 \mathrm{kHz}$ down to $0.40 \mathrm{~Hz}$, followed by a ramp signal for the next $2.5 \mathrm{~s}$ to record CVs. The Fourier transform EIS (FTEIS), in which a full EIS spectrum is acquired from a small potential step signal by going through a number of procedures, have been well established via a series of publications [15,92-96]. Figures $4 \mathrm{~b}, \mathrm{c}$ show a series of impedance spectra and CVs thus obtained, respectively, both at every $2.5 \mathrm{~s}$. While CVs show a maximum decrease in their peak heights by only about $46 \%$ in $20 \mathrm{~min}$, the $R_{\mathrm{ct}}$ value showed a maximum increase by about $480 \%$ during the same period while the reaction was proceeding after a solution containing $\mathrm{HbA}_{1 \mathrm{c}}$ was added to the boronic acid covered electrode immersed in the solution. A very similar observation was reported for a serotonin sensor, in which an (R)-lipo-diaza-18-crown-6 SAM was used to capture serotonin molecules in the presence of the $\left[\mathrm{Fe}(\mathrm{CN})_{6}\right]^{3-/ 4-}$ redox indicator [91]. In the latter case, however, the $R_{\mathrm{ct}}$ value was decreased upon addition of serotonin instead due to a different chemistry taking place from that for the $\mathrm{HbA}_{1 \mathrm{c}}$ sensor. Both cases indicate that monitoring the change in $R_{\mathrm{ct}}$ values is much more sensitive than monitoring currents by voltammetric or amperometric methods. We should also point out that the FTEIS technique, although we have not described in detail here, allows one to record a full spectrum in a short period, as short as less than $0.1 \mathrm{~s}$ depending on the electrochemical reversibility of the redox indicator used [92-96]. 
Figure 4. Comparison of impedance and $\mathrm{CV}$ measurements during the reaction of $\mathrm{HbA}_{1 \mathrm{c}}$ with the thiophene-3-boronic acid SAM [90]: (a) the waveform applied to the electrode to sequentially obtain FTEIS and CV data, (b) a series of Nyquist plots, (c) the ratio of $R_{\mathrm{ct}(\mathrm{t})}$ and $R_{\mathrm{ct} \text {,initial, }}$ and (d) a series of CVs. Note the $480 \%$ increase in impedance $v s$. the $46 \%$ decrease in peak heights.

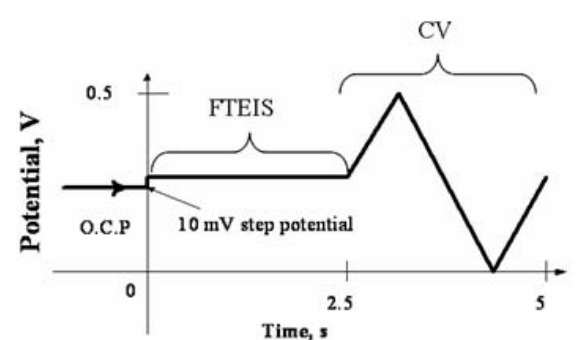

(a)

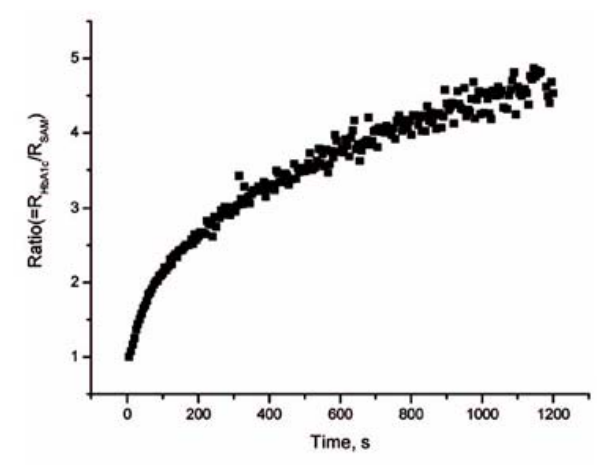

(c)

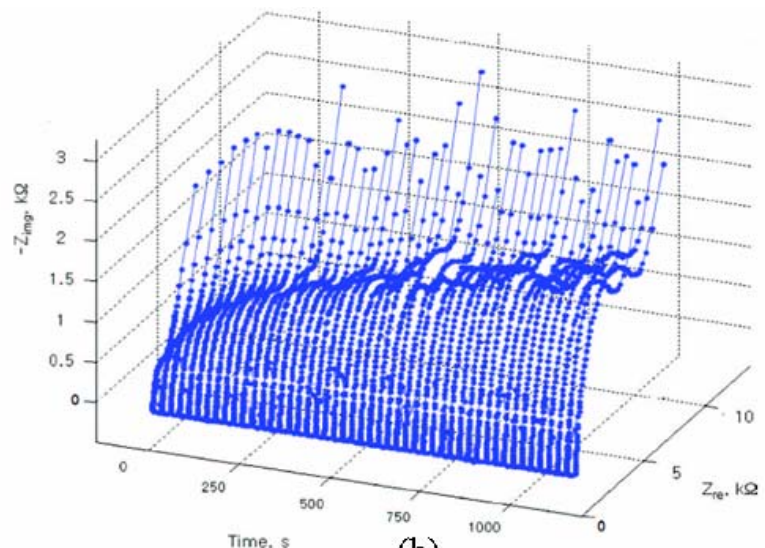

(b)

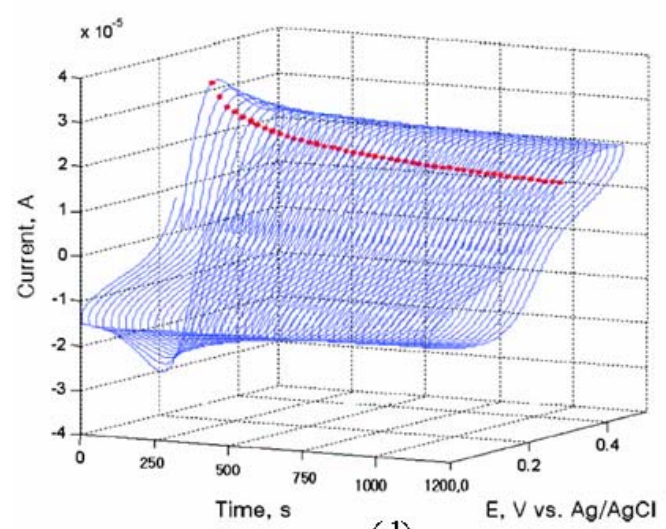

(d)

\section{Conclusions}

We have briefly reviewed recent advances made in DNA sensors employing EIS as a detection tool among many other biosensors using similar platforms [97-101]. Three main types of platforms such as SAMs, conducting polymers, and metal or semiconductor nanoparticles have been covered in this review. As pointed out, the selectivity is provided by choosing an appropriate chemistry taking place on the electrode surface, which renders the EIS measurements label free. In this area, working out a creative chemistry on the electrode surface is a key strategy to developing more selective and sensitive DNA or other biosensors. We have also demonstrated that the EIS method can be significantly more sensitive than their traditional counterparts such as amperometric, voltammetric, and potentiometric measurements as a detection tool.

Despite the advantages of EIS as a detection tool described earlier in this review, it also suffers from a few disadvantages and limitations. In most cases, its sensitivity still cannot match that of the fluorescence detection as the sensitivity of the latter method is directly related to the intensity of the excitation source. Another limitation arises from the requirement that the EIS detection must be used 
only at an electrode, while any surfaces may serve as a platform for the fluorescence detection. Again, we described how the surface chemistry can enhance the sensitivity as well as the selectivity.

It often takes too long to acquire an EIS spectrum in a reasonably wide frequency range employing the traditional frequency response analyzer. For this reason, a series of relative values of impedances or capacitances at a fixed frequency have been frequently utilized for real-time sensing [54,57], which is useful for improving the binding/unbinding accuracy and determining the affinity constant. However, we also notice that FTEIS experiments reduce the impedance measurement times by orders of magnitudes [88-92]. It is thus possible to use the EIS measurements for real-time monitoring of the reaction kinetics at the electrode surface and also as a detection tool when scanning an array of hundreds of electrodes on a DNA chip. The next step of the development of the DNA or other biochips should be the incorporation of the capability of making real time measurements so that many DNA or other samples would be analyzed by simply scanning across the chip. More work on the use of nanostructures to enhance the sensitivity of biosensors, as well as the incorporation of FTEIS for analyzing a large number of samples, should represent an important breakthrough to be achieved in the not too distant time to come.

\section{Acknowledgements}

This work was supported by the WCU program funded to the Ulsan National Institute of Science and Technology (UNIST) by the Korea Research Foundation.

\section{References and Notes}

1. Liu, J.; Cao, Z.; Lu, Y. Functional nucleic acid sensors. Chem. Rev. 2009, 109, 1948-1998.

2. Wilson, J.N.; Yin, N.T.; Kool, E.T. Efficient quenching of oligomeric fluorophores on a DNA backbone. J. Am. Chem. Soc. 2007, 129, 15426-15427.

3. Yang, R.; Jin, J.; Chen, Y.; Shao, N.; Kang, H.; Xiao, Z.; Tang, Z.; Wu, Y.; Zhu, Z.; Tan, W. Carbon nanotube-quenched fluorescent oligonucleotides: Probes that fluoresce upon hybridization. J. Am. Chem. Soc. 2008, 130, 8351-8358.

4. Baselt, D.R.; Lee, G.U.; Natesan, M.; Metzger, S.W.; Sheehan, P.E.; Colton, R.J. A biosensor based on magnetoresistance technology. Biosens. Bioelectron. 1998, 13, 731-739.

5. Niu, S.Y.; Li, Q.Y.; Ren, R.; Zhang, S.S. Enzyme-enhanced fluorescence detection of DNA on etched optical fibers. Biosens. Bioelectron. 2009, 24, 2943-2946.

6. Guan, J.-G.; Miao, Y.-Q.; Zhang, Q.-J. Impedimetric biosensors. J. Biosci. Bioeng. 2004, 97, 219-226.

7. Cash, K.J.; Heeger, A.J.; Plaxco, K.W.; Xiao, Y. Optimization of a Reusable, DNA Pseudoknot-Based Electrochemical Sensor for Sequence-Specific DNA Detection in Blood Serum. Anal. Chem. 2009, 81, 656-661.

8. Zhang, S.S.; Xia, J.P.; Li, X.M. Electrochemical Biosensor for Detection of Adenosine Based on Structure-Switching Aptamer and Amplification with Reporter Probe DNA Modified Au Nanoparticles. Anal. Chem. 2008, 80, 8382-8388. 
9. Zuo, S.H.; Zhang, L.F.; Yuan, H.H.; Lan, M.B.; Lawrance, G.A.; Wei, G. Electrochemical detection of DNA hybridization by using a zirconia modified renewable carbon paste electrode. Bioelectrochemistry 2009, 74, 223-226.

10. Singh, R.; Prasad, R.; Sumana, G.; Arora, K.; Sood, S.; Gupta, R.K.; Malhotra, B.D. STD sensor based on nucleic acid functionalized nanostructured polyaniline. Biosens. Bioelectron. 2009, 24, 2232-2238.

11. Yang, T.; Zhang, W.; Du, M.; Jiao, K. A PDDA/poly(2,6-pyridinedicarboxylic acid)-CNTs composite film DNA electrochemical sensor and its application for the detection of specific sequences related to PAT gene and NOS gene. Talanta 2008, 75, 987-994.

12. Shiddiky, M.J.A.; Rahman, M.A.; Cheol, C.S.; Shim, Y.B. Fabrication of disposable sensors for biomolecule detection using hydrazine electrocatalyst. Anal. Biochem. 2008, 379, 170-175.

13. Pournaghi-Azar, M.H.; Alipour, E.; Zununi, S.; Froohandeh, H.; Hejazi, M.S. Direct and rapid electrochemical biosensing of the human interleukin-2 DNA in unpurified polymerase chain reaction (PCR)-amplified real samples. Biosens. Bioelectron. 2008, 24, 524-530.

14. Evtugyn, G.A.; Goldfarb, O.E.; Budnikov, H.C.; Ivanov, A.N.; Vinter, V.G. Amperometric DNA-peroxidase sensor for the detection of pharmaceutical preparations. Sensors 2005, 5, 364-376.

15. Park, S.M.; Yoo, J.S. Electrochemical impedance spectroscopy for better electrochemical measurements. Anal. Chem. 2003, 75, 455A-461A.

16. Tang, L.; Zeng, G.; Shen, G.; Li, Y.; Liu, C.; Li, Z.; Luo, J.; Fan, C.; Yang, C. Sensitive detection of lip genes by electrochemical DNA sensor and its application in polymerase chain reaction amplicons from Phanerochaete chrysosporium. Biosens. Bioelectron. 2009, 24, 1474-1479.

17. Patel, M.K.; Solanki, P.R.; Seth, S.; Gupta, S.; Khare, S.; Kumar, A.; Malhotra, B.D. CtrA gene based electrochemical DNA sensor for detection of meningitis. Electrochem. Commun. 2009, 11, 969-973.

18. Katz, E.; Willner, I. Probing Biomolecular Interactions at Conductive and Semiconductive Surfaces by Impedance Spectroscopy: Routes to Impedimetric Immunosensors, DNA-Sensors, and Enzyme Biosensors. Electroanalysis 2003, 15, 913-947.

19. Berggren, C.; Bjarnason, B.; Johansson, G. Capacitive Biosensors. Electroanalysis 2001, 13, 173-180.

20. Ito, T.; Hosokawa, K.; Maeda, M. Detection of single-base mismatch at distal end of DNA duplex by electrochemical impedance spectroscopy. Biosens. Bioelectron. 2007, 22, 1816-1819.

21. Li, D.L.; Zou, X.Q.; Shen, Q.; Dong, S.J. Kinetic study of DNA/DNA hybridization with electrochemical impedance spectroscopy. Electrochem. Commun. 2007, 9, 191-196.

22. Long, Y.T.; Li, C.Z.; Kraatz, H.B.; Lee, J.S. AC impedance spectroscopy of native DNA and MDNA. Biophys. J. 2003, 84, 3218-3225.

23. Long, Y.T.; Li, C.Z.; Sutherland, T.C.; Kraatz, H.B.; Lee, J.S. Electrochemical detection of single-nucleotide mismatches: application of M-DNA. Anal. Chem. 2004, 76, 4059-4065.

24. Li, X.; Lee, J.S.; Kraatz, H.B. Electrochemical detection of single-nucleotide mismatches using an electrode microarray. Anal. Chem. 2006, 78, 6096-6101. 
25. Li, X.; Zhou, Y.; Sutherland, T.C.; Baker, B.; Lee, J.S.; Kraatz, H.B. Chip-based microelectrodes for detection of single-nucleotide mismatch. Anal. Chem. 2005, 77, 5766-5769.

26. Wang, Y.; Li, C.; Li, X.; Li, Y.; Kraatz, H.-B. Unlabeled hairpin-DNA probe for the detection of single-nucleotide mismatches by electrochemical impedance spectroscopy. Anal. Chem. 2008, 80, 2255-2260.

27. Bin, X.; Kraatz, H.-B. Interaction of metal ions and DNA films on gold surfaces: an electrochemical impedance study. Analyst 2009, 134, 1309-1313.

28. Patolsky, F.; Lichtenstein, A.; Willner, I. Electronic transduction of DNA sensing processes on surfaces: Amplification of DNA detection and analysis of single-base mismatches by tagged liposomes. J. Am. Chem. Soc. 2001, 123, 5194-5205.

29. Lucarelli, F.; Marrazza, G.; Mascini, M. Enzyme-based impedimetric detection of PCR products using oligonucleotide-modified screen-printed gold electrodes. Biosens. Bioelectron. 2005, 20 , 2001-2009.

30. Herne, T.M.; Tarlov, M.J. Characterization of DNA probes immobilized on gold surfaces. J. Am. Chem. Soc. 1997, 119, 8916-8920.

31. Pan, C.F.; Guo, M.L.; Nie, Z.; Xiao, X.L.; Yao, S.Z. Aptamer-based electrochemical sensor for label-free recognition and detection of cancer cells. Electroanalysis 2009, 21, 1321-1326.

32. Keighley, S.D.; Estrela, P.; Li, P.; Mighorato, P. Optimization of label-free DNA detection with electrochemical impedance spectroscopy using PNA probes. Biosens. Bioelectron. 2008, 24, 906-911.

33. Kjällman, T.H.M.; Peng, H.; Soeller, C.; Travas-Sejdic, J. Effect of probe density and hybridization temperature on the response of an electrochemical hairpin-DNA sensor. Anal. Chem. 2008, 80, 9460-9466.

34. Kafka, J.; Pänke, O.; Abendroth, B.; Lisdat, F. A label-free DNA sensor based on impedance spectroscopy. Electrochim. Acta 2008, 53, 7467-7474.

35. Snejdarkova, M.; Svobodova, L.; Nikolelis, D.P.; Wang, J.; Hianik, T. Acetylcholine biosensor based on dendrimer layers for pesticides detection. Electroanalysis 2003, 15, 1185-1191.

36. Svobodová, L.; Šnejdárková, M.; Hianik, T. Properties of glucose biosensors based on dendrimer layers. Effect of enzyme immobilization. Anal. Bioanal. Chem. 2002, 373, 735-741.

37. Svobodová, L.; Šnejdárková, M.; Tóth, K.; Gyurcsanyi, R.E.; Hianik, T. Properties of mixed alkanethiol-dendrimer layers and their applications in biosensing. Bioelectrochemistry 2004, 63, 285-289.

38. Zhu, N.; Gu, Y.; Chang, Z.; He, P.; Fang, Y. PAMAM dendrimers-based DNA biosensors for electrochemical detection of DNA hybridization. Electroanalysis 2006, 18, 2107-2114.

39. Zhu, N.; Gao, H.; Gu, Y.; Xu, Q.; He, P.; Fang, Y. PAMAM dendrimer-enhanced DNA biosensors based on electrochemical impedance spectroscopy. Analyst 2009, 134, 860-866.

40. Park, J.Y.; Kwon, S.H.; Park, J.W.; Park, S.M. Label-free detection of DNA molecules on the dendron based self-assembled monolayer by electrochemical impedance spectroscopy. Anal. Chim. Acta 2008, 619, 37-42.

41. Li, X.; Song, H.; Nakatani, K.; Kraatz, H.-B. Exploiting small molecule binding to DNA for the detection of single-nucleotide mismatches and their base environment. Anal. Chem. 2007, 79, 2552-2555. 
42. Gong, H.; Zhong, T.; Gao, L.; Li, X.; Bi, L.; Kraatz, H.-B. Unlabeled hairpin DNA for electrochemical detection of single-nucleotide mismatches based on MutS-DNA interactions, Anal. Chem. 2009, 81, 8639-8643.

43. Rahman, M.A.; Kumar, P.; Park, D.S.; Shim, Y.B. Electrochemical sensors based on organic conjugated polymers. Sensors 2008, 8, 118-141.

44. Minehan, D.S.; Marx, K.A.; Tripathy, S.K. Kinetics of DNA binding to electrically conducting polypyrrole films. Macromolecules 1994, 27, 777-783.

45. Paleček, E. Past, present and future of nucleic acids electrochemistry. Talanta 2002, 56, 809-819.

46. Peng, H.; Soeller, C.; Cannell, M.B.; Bowmaker, G.A.; Cooney, R.P.; Travas-Sejdic, J. Electrochemical detection of DNA hybridization amplified by nanoparticles. Biosens. Bioelectron. 2006, 21, 1727-1736.

47. Travas-Sejdic, J.; Peng, H.; Cooney, R.P.; Bowmaker, G.A.; Cannell, M.B.; Soeller, C. Amplification of a conducting polymer-based DNA sensor signal by CdS nanoparticles. Curr. Appl. Phys. 2006, 6, 562-566.

48. Lassalle, N.; Mailley, P.; Vieil, E.; Livache, T.; Roget, A.; Correia, J.P.; Abrantes, L.M. Electronically conductive polymer grafted with oligonucleotides as electrosensors of DNA: Preliminary study of real time monitoring by in situ techniques. J. Electroanal. Chem. 2001, 509, 48-57.

49. Delabouglise, D.; Roncali, J.; Lemaire, M.; Garnier, F. Control of the lipophilicity of polypyrrole by 3-alkyl substitution. J. Chem.l Soc. Chem. Commun. 1989, 8, 475-477.

50. Peng, H.; Soeller, C.; Vigar, N.; Kilmartin, P.A.; Cannell, M.B.; Bowmaker, G.A.; Cooney, R.P.; Travas-Sejdic, J. Label-free electrochemical DNA sensor based on functionalised conducting copolymer. Biosens. Bioelectron. 2005, 20, 1821-1828.

51. Travas-Sejdic, J.; Peng, H.; Kilmartin, P.A.; Cannell, M.B.; Bowmaker, G.A.; Cooney, R.P.; Soeller, C. DNA sensor based on functionalized polypyrrole. Synthet. Metal. 2005, 152, 37-40.

52. Peng, H.; Soeller, C.; Travas-Sejdic, J. Novel conducting polymers for DNA sensing. Macromolecules 2007, 40, 909-914.

53. Peng, H.; Soeller, C.; Vigar, N.A.; Caprio, V.; Travas-Sejdic, J. Label-free detection of DNA hybridization based on a novel functionalized conducting polymer. Biosens. Bioelectron. 2007, 22, 1868-1873.

54. Lee, T.Y.; Shim, Y.B. Direct DNA hybridization detection based on the oligonucleotide-functionalized conductive polymer. Anal. Chem. 2001, 73, 5629-5632.

55. Peng, H.; Zhang, L.; Spires, J.; Soeller, C.; Travas-Sejdic, J. Synthesis of a functionalized polythiophene as an active substrate for a label-free electrochemical genosensor. Polymer 2007, 48, 3413-3419.

56. Spires, J.B.; Peng, H.; Williams, D.E.; Wright, B.E.; Soeller, C.; Travas-Sejdic, J. The effect of the oxidation state of a terthiophene-conducting polymer and of the presence of a redox probe on its gene-sensing properties. Biosens. Bioelectron. 2008, 24, 928-933.

57. Gautier, C.; Esnault, C.; Cougnon, C.; Pilard, J.F.; Casse, N.; Chénais, B. Hybridization-induced interfacial changes detected by non-Faradaic impedimetric measurements compared to Faradaic approach. J. ElectroAnal. Chem. 2007, 610, 227-233. 
58. Gautier, C.; Cougnon, C.; Pilard, J.F.; Casse, N. Label-free detection of DNA hybridization based on EIS investigation of conducting properties of functionalized polythiophene matrix. $J$. ElectroAnal. Chem. 2006, 587, 276-283.

59. Gautier, C.; Cougnon, C.; Pilard, J.F.; Casse, N.; Chénais, B.; Laulier, M. Detection and modelling of DNA hybridization by EIS measurements. Mention of a polythiophene matrix suitable for electrochemically controlled gene delivery. Biosens. Bioelectron. 2007, 22, 2025-2031.

60. Davis, F.; Hughes, M.A.; Cossins, A.R.; Higson, S.P.J. Single gene differentiation by DNA-modified carbon electrodes using an AC impedimetric approach. Anal. Chem. 2007, 79, 1153-1157.

61. Davis, F.; Nabok, A.V.; Higson, S.P.J. Species differentiation by DNA-modified carbon electrodes using an ac impedimetric approach. Biosens. Bioelectron. 2005, 20, 1531-1538.

62. Weng, J.; Zhang, J.; Li, H.; Sun, L.; Lin, C.; Zhang, Q. Label-free DNA sensor by boron-doped diamond electrode using an ac impedimetric approach. Anal. Chem. 2008, 80, 7075-7083.

63. Gu, H.; Su, X.D.; Loh, K.P. Electrochemical impedance sensing of DNA hybridization on conducting polymer film-modified diamond. J. Phys. Chem. B 2005, 109, 13611-13618.

64. Zhou, N.; Yang, T.; Jiang, C.; Du, M.; Jiao, K. Highly sensitive electrochemical impedance spectroscopic detection of DNA hybridization based on Au-nano-CNT/PAN(nano) films. Talanta 2009, 77, 1021-1026.

65. Zhang, W.; Yang, T.; Yin, C.; Li, G.; Jiao, K. An enhanced strategy using poly(m-aminobenzene sulfonic acid) nanofibres for rapid detection of DNA oxidative damage induced by hollow TiO2 nanocubes. Electrochem. Commun. 2009, 11, 783-786.

66. Yang, T.; Zhou, N.; Zhang, Y.; Zhang, W.; Jiao, K.; Li, G. Synergistically improved sensitivity for the detection of specific DNA sequences using polyaniline nanofibers and multi-walled carbon nanotubes composites. Biosens. Bioelectron. 2009, 24, 2165-2170.

67. Wang, J. Nanoparticle-based electrochemical DNA detection. Anal. Chim. Acta 2003, 500, 247-257.

68. Xu, Y.; Cai, H.; He, P.G.; Fang, Y.Z. Probing DNA hybridization by impedance measurement based on CdS-oligonucleotide nanoconjugates. Electroanalysis 2004, 16, 150-155.

69. Zhang, K.; Ma, H.; Zhang, L.; Zhang, Y. Fabrication of a sensitive impedance biosensor of DNA hybridization based on gold nanoparticles modified gold electrode. Electroanalysis 2008, 20, 2127-2133.

70. Bonanni, A.; Esplandiu, M.J.; del Valle, M. Signal amplification for impedimetric genosensing using gold-streptavidin nanoparticles. Electrochim. Acta 2008, 53, 4022-4029.

71. Bonanni, A.; Esplandiu, M.J.; del Valle, M. Impedimetric genosensors employing COOH-modified carbon nanotube screen-printed electrodes. Biosens. Bioelectron. 2009, 24, 2885-2891.

72. He, P.L.; Shen, L.; Cao, Y.H.; Lia, D.F. Ultrasensitive electrochemical detection of proteins by amplification of aptamer-nanoparticle bio bar codes. Anal. Chem. 2007, 79, 8024-8029.

73. Li, C.Z.; Liu, Y.L.; Luong, J.H.T. Impedance sensing of DNA binding drugs using gold substrates modified with gold nanoparticles. Anal. Chem. 2005, 77, 478-485. 
74. Zhang, K.I.; Ma, H.Y.; Zhang, L.P.; Zhang, Y.Z. Fabrication of a Sensitive Impedance Biosensor of DNA Hybridization Based on Gold Nanoparticles Modified Gold Electrode. Electroanalysis 2008, 20, 2127-2133.

75. Li, X.X.; Shen, L.H.; Zhang, D.D.; Qi, H.L.; Gao, Q.; Ma, F.; Zhang, C.X. Electrochemical impedance spectroscopy for study of aptamer-thrombin interfacial interactions. Biosens. Bioelectron. 2008, 23, 1624-1630.

76. Deng, C.Y.; Chen, J.H.; Nie, Z.; Wang, M.D.; Chu, X.C.; Chen, X.L.; Xiao, X.L.; Lei, C.Y.; Yao, S.Z. Impedimetric aptasensor with femtomolar sensitivity based on the enlargement of surface-charged gold nanoparticles. Anal. Chem. 2009, 81, 739-745.

77. Hassen, W.M.; Chaix, C.; Abdelghani, A.; Bessueille, F.; Leonard, D.; Jaffrezic-Renault, N. An impedimetric DNA sensor based on functionalized magnetic nanoparticles for HIV and HBV detection. Sensor. Actuator. B-Chem. 2008, 134, 755-760.

78. Suehiro, J.; Ikeda, N.; Ohtsubo, A.; Imasaka, K. Fabrication of bio/nano interfaces between biological cells and carbon nanotubes using dielectrophoresis. Microfluid. Nanofluid. 2008, 5, 741-747.

79. Steinhoff, G.; Purrucker, O.; Tanaka, M.; Stutzmann, M.; Eickhoff, M. AlxGa1-xN-a new material system for biosensors. Adv. Funct. Mater. 2003, 13, 841-846.

80. Kang, B.S.; Ren, F.; Wang, L.; Lofton, C.; Tan, W.W.; Pearton, S.J.; Dabiran, A.; Osinsky, A.; Chow, P.P. Electrical detection of immobilized proteins with ungated AlGaNGaN high-electron-mobility Transistors. Appl. Phys. Lett. 2005, 87, 1-3.

81. Kang, B.S.; Wang, H.T.; Lele, T.P.; Tseng, Y.; Ren, F.; Pearton, S.J.; Johnson, J.W.; Rajagopal, P.; Roberts, J.C.; Piner, E.L.; Linthicum, K.J. Prostate specific antigen detection using AlGaN/GaN high electron mobility transistors. Appl. Phys. Lett. 2007, 91, 112106-1-112106-3.

82. Chen, C.P.; Ganguly, A.; Wang, C.H.; Hsu, C.W.; Chattopadhyay, S.; Hsu, Y.K.; Chang, Y.C.; Chen, K.H.; Chen, L.C. Label-free dual sensing of DNA molecules using GaN nanowires. Anal. Chem. 2009, 81, 36-42.

83. Zhu, N.; Chang, Z.; He, P.; Fang, Y. Electrochemical DNA biosensors based on platinum nanoparticles combined carbon nanotubes. Anal. Chim. Acta 2005, 545, 21-26.

84. Li, J.; Liu, Q.; Liu, Y.; Liu, S.; Yao, S. DNA biosensor based on chitosan film doped with carbon nanotubes. Anal. Biochem. 2005, 346, 107-114.

85. Daniel, S.; Rao, T.P.; Rao, K.S.; Rani, S.U.; Naidu, G.R.K.; Lee, H.Y.; Kawai, T. A review of DNA functionalized/grafted carbon nanotubes and their characterization. Sensor. Actuator. B-Chem. 2007, 122, 672-682.

86. Balasubramanian, K.; Burghard, M. Biosensors based on carbon nanotubes. Anal. BioAnal. Chem. 2006, 385, 452-468.

87. Jiang, C.; Yang, T.; Jiao, K.; Gao, H. A DNA electrochemical sensor with poly-l-lysine/single-walled carbon nanotubes films and its application for the highly sensitive EIS detection of PAT gene fragment and PCR amplification of NOS gene. Electrochim. Acta 2008, 53, 2917-2924.

88. Zhang, W.; Yang, T.; Zhuang, X.; Guo, Z.; Jiao, K. An ionic liquid supported CeO2 nanoshuttles-carbon nanotubes composite as a platform for impedance DNA hybridization sensing. Biosens. Bioelectron. 2009, 24, 2417-2422. 
89. Drummond, T.G.; Hill, M.G.; Barton, J.K. Electrochemical DNA sensors. Nature Biotech. 2003, 21, 1192-1199.

90. Park, J.Y.; Chang, B.Y.; Nam, H.; Park, S.M. Selective electrochemical sensing of glycated hemoglobin $\left(\mathrm{HbA}_{1 \mathrm{c}}\right)$ on thiophene-3-boronic acid self-assembled monolayer covered gold electrodes. Anal. Chem. 2008, 80, 8035-8044.

91. Park, J.Y.; Lee, Y.S.; Kim, B.H.; Park, S.M. (R)-Lipo-diaza-18-crown-6 self-assembled monolayer as a selective serotonin receptor. Anal. Chem. 2009, 80, 4986-4993.

92. Yoo, J.-S.; Park, S.-M. An electrochemical impedance measurement technique employing Fourier transform. Anal. Chem. 2000, 72, 2035-2041.

93. Yoo, J.-S.; Song, I; Lee, J.-H.; Park, S.-M. Real-time impedance measurements during electrochemical experiments and their application to aniline oxidation. Anal. Chem. 2003, 75, 3294-3300.

94. Park, S.-M.; Yoo, J.-S.; Chang, B.-Y.; Ahn E.-S. Novel instrumentation in electrochemical impedance spectroscopy and a full description of an electrochemical system. Pure Appl. Chem. 2006, 78, 1069-1080.

95. Chang, B.-Y.; Park, S.-M. Integrated description of electrode/electrolyte interfaces based on equivalent circuits and its verification using impedance measurements. Anal. Chem. 2006, 78, 1052-1060.

96. Chang, B.-Y.; Park, S.-M. Fourier transform analysis of chronoamperometric currents obtained during staircase voltammetric experiments. Anal. Chem. 2007, 79, 4892-4899.

97. Lee, J.-Y.; Park, S.-M. Electrochemistry of Guest Molecules in Thiolated Cyclodextrin Self-Assembled Monolayers : An Implication for Size-Selective Sensors J. Phys. Chem. B 1998, 102, 9940-9945.

98. Choi, S.-J.; Choi, B.-G.; Park, S.-M. Electrochemical Sensor for Electrochemically Inactive $\beta$-D(+)-Glucose Using $\alpha$-Cyclodextrin Template Molecules. Anal. Chem. 2002, 74, 1998-2002.

99. Park, J.-Y.; Kim, B.-C.; Park, S.-M. Molecular recognition of protonated polyamines at calix[4]crown-5 self-assembled monolayer modified electrodes by impedance measurements. Anal. Chem. 2007, 79, 1890-1896.

100. Park, J.-Y.; Lee, Y.S.; Kim, B.H.; Park, S.-M. Label-free detection of antibody-antigen interactions on (R)-lipo-diaza-18-crown-6 self-assembled monolayer modified gold electrodes. Anal. Chem. 2008, 80, 4986-4993.

101. Yeo, J; Park, J.-Y.; Bae, W.J.; Lee, Y.S.; Kim, B.H.; Cho, Y.; Park, S.-M. Label-free electrochemical detection of the p53 core domain protein on its antibody immobilized electrode. Anal. Chem. 2009, 81, 4770-4777.

(C) 2009 by the authors; licensee Molecular Diversity Preservation International, Basel, Switzerland. This article is an open-access article distributed under the terms and conditions of the Creative Commons Attribution license (http://creativecommons.org/licenses/by/3.0/). 